\title{
Microdispersive superconductors in ceramic and polymeric matrix
}

\author{
V A ALEKSEEV, V M BARANOVSKY, A A VEDENOV, A V \\ VELICHKO, L L ZAYTZEVA, A S KOVALENKO, M I \\ KONAREV, G F LESHENKO, T S MYLNIKOVA, A YA \\ PARSHIN, YU F RYZHKOV, B S SKIDAN, A I SUKHIH, N A \\ USOV, L I FEKLINA and N V SHISHKOV
}

Kurchatov Institute of Atomic Energy, Moscow, USSR

\begin{abstract}
The influences of the host material on the superconducting properties of the composite material are studied in the following cases: (i) niobium powder-aluminium oxide, (ii) technetium - rare earth oxides and (iii) $\mathrm{Nb}_{3} \mathrm{~S}_{n}$ powder- - unsaturated polymer of fluorine derivative of ethylene. The critical temperatures, critical magnetic fields and the $I-V$ characteristics of these systems are discussed.
\end{abstract}

Keywords. Microdispersive superconductors; ceramic matrix; polymeric matrix.

Studies on the influence of host materials on the superconducting properties of the composite material are of great scientific and technical interest. If the microdispersive superconductor is introduced into the matrix with high Debye temperature and high dielectric constant or with various conductivity mechanisms, one may investigate the dependence of the superconducting properties of metals on the matrix material. To avoid the shunting effect due to matrix metal it is necessary (i) to determine the limited metal concentration where the superconducting current exists and (ii) to reach the largest specific surface of contacts in the sample by preparation of very thin component powders $\left(10^{2}-10^{1} \AA\right)$.

These systems are interesting for practical purposes due to the possibility of making superconducting materials with very high resistivity before their transition into the superconducting state. It may be important for superconducting switching devices and superconducting sensors of electromagnetic radiation.

Liquid eutectic alloy In-Ga-Sn in porous glass matrix was studied earlier (Alekseev et al 1975). It was found that the critical temperature did not increase but the "normal alloy-superconductor transition" was sharper $(\Delta T \sim 0.8 \mathrm{~K})$ than the one in the alloy without glass matrix In-Ga-Sn $(\Delta T \sim 1.6 \mathrm{~K})\left(T_{c} \sim 4.9 \mathrm{~K}\right)$.

Glass and other dielectric matrices have limited electronic properties for studying the matrix material dependence on $T_{c}$. We therefore attempted to solve the first of the two problems mentioned earlier by determining the metal concentration in the matrix at which the metal-insulator transition occurs. The mix of alumina powder and metal $(\mathrm{Nb})$ powder (grain size of $\sim 5 \mu \mathrm{m}$ ) was used as the model system.

Samples of various volume concentrations of components were sintered at $1800{ }^{\circ} \mathrm{C}$. As a result, superconducting cermets $\mathrm{Nb}-\mathrm{Al}_{2} \mathrm{O}_{3}$ with different metal concentration were obtained. For cermets $T_{c}$ and $J_{c}($ at $T=4 \cdot 2 \mathrm{~K})$ were measured at $H=0 \mathrm{~T}$. It is shown that $T_{c}$ changes slightly with $\mathrm{Nb}$ concentration $\left(T_{c}=5-6 \mathrm{~K}\right)$. The resistivity $\rho$ of the cermets before their transition to superconducting state is $\sim 10^{-1}-10^{-2} \Omega \mathrm{cm}$ and the metal volume concentration and $\rho$ decreases abruptly to $20^{\circ} \%$ and $\sim 10^{-4} \Omega \mathrm{cm}$ respectively.

Cermets with $\mathrm{Nb}$ concentration $>20^{\circ}$ o indicate abrupt transition to superconduc- 
tion state and those $<20 \%$ indicate step-like transition as shown in figure 1 (curves 1 and 2 respectively).

We assume that at low volume concentration of $\mathrm{Nb}$ the contacts on boundary metalceramics which were shunted by metal masses of matrix at larger metal concentrations begin to play an important role.

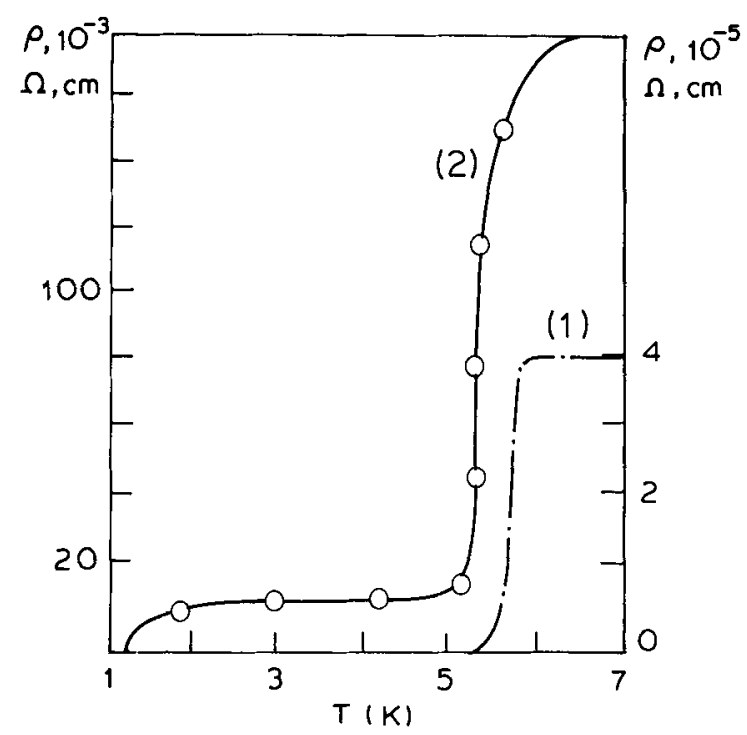

Figure 1. Transition to superconducting state in Nb-alumina cermets.

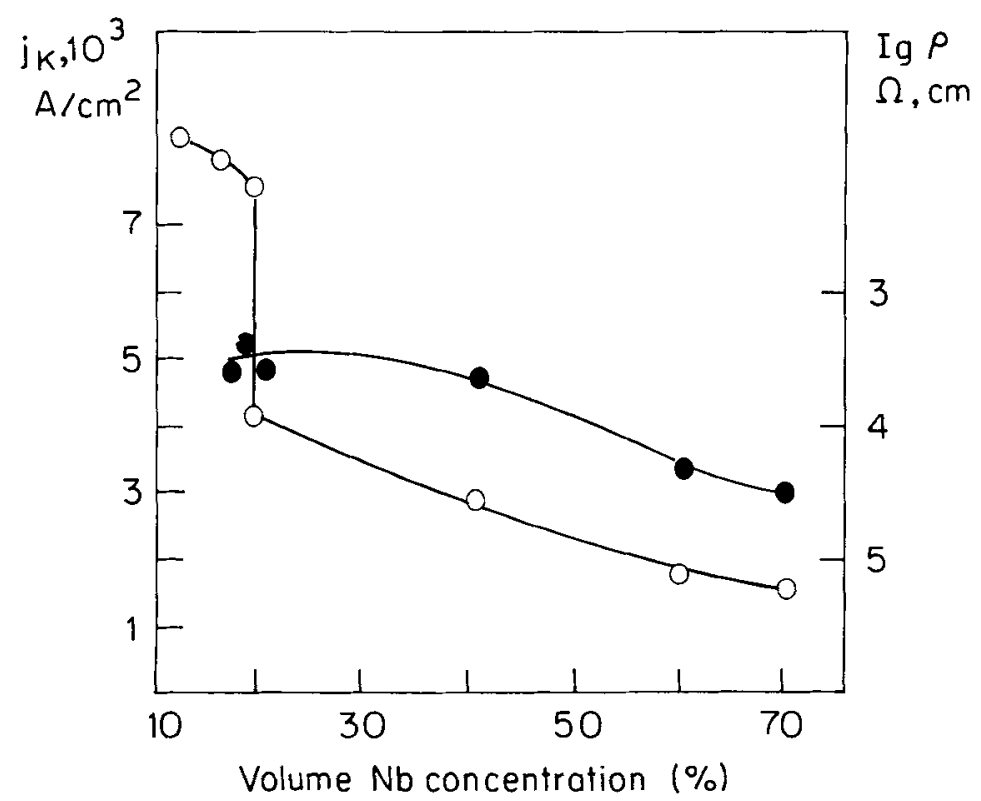

Figure 2. Critical current density versus $\mathrm{Nb}$ concentration for $\mathrm{Nb}-\mathrm{Al}_{2} \mathrm{O}_{3}$ - cermets. 
The sharp decrease of $\rho$ with increasing $\mathrm{Nb}$ concentration agrees qualitatively with the results of model experiments on small metallic balls (Alekseev et al 1975).

It is interesting that $J_{\mathrm{c}}$ of cermet samples of $\phi 1 \mathrm{~mm}$ changes with $\mathrm{Nb}$ concentration very slightly without sharp jumps (figure 2).

To study the influence of the ceramic matrix on $T_{c}$ we have prepared the cermets "technetium-rare-earth oxide" $\mathrm{R}_{2} \mathrm{O}_{3}(\mathrm{R}=\mathrm{La}, \mathrm{Sm}, \mathrm{Eu}, \mathrm{Ga}, \mathrm{Tb}, \mathrm{Ho}, \mathrm{Er}, \mathrm{Yb}, \mathrm{Lu})$ (Alekseev et al 1977). The resistance of the samples was measured by a four-probe method, and the temperature measured using an $\mathrm{Fe}-\mathrm{Au}$ thermocouple. The results are shown in figure 3. $T_{c}$ of base technetium was $\sim 7.45 \mathrm{~K}$. It is found that the cermets Technetium $\mathrm{R}_{2} \mathrm{O}_{3}$ have higher $T_{c}$ compared with metallic Technetium. The Technetium- $\mathrm{La}_{2} \mathrm{O}_{3}$ cermet indicates abnormally high $T_{c}$. The resistance changes sharply at $T=12 \mathrm{~K}$. It is obviously connected with the phase transition in lanthanum oxide at this temperature. The onset of superconducting transition in Technetium- $\mathrm{La}_{2} \mathrm{O}_{3}$ cermet takes place at $10 \cdot 25-10 \cdot 5 \mathrm{~K}$.

Other cermets indicate higher $T_{c}$ than $T_{c}$ of the pure Technetium, but it was observed that $T_{c}$ of these cermets decreases with increase of rare-earth element atomic number. All measured cermets indicate higher critical magnetic field than one of pure Technetium (for example $H_{c}$ of Technetium- $\mathrm{Sm}_{2} \mathrm{O}_{3}$ is 10 times greater than $H_{c}$ of pure Technetium).

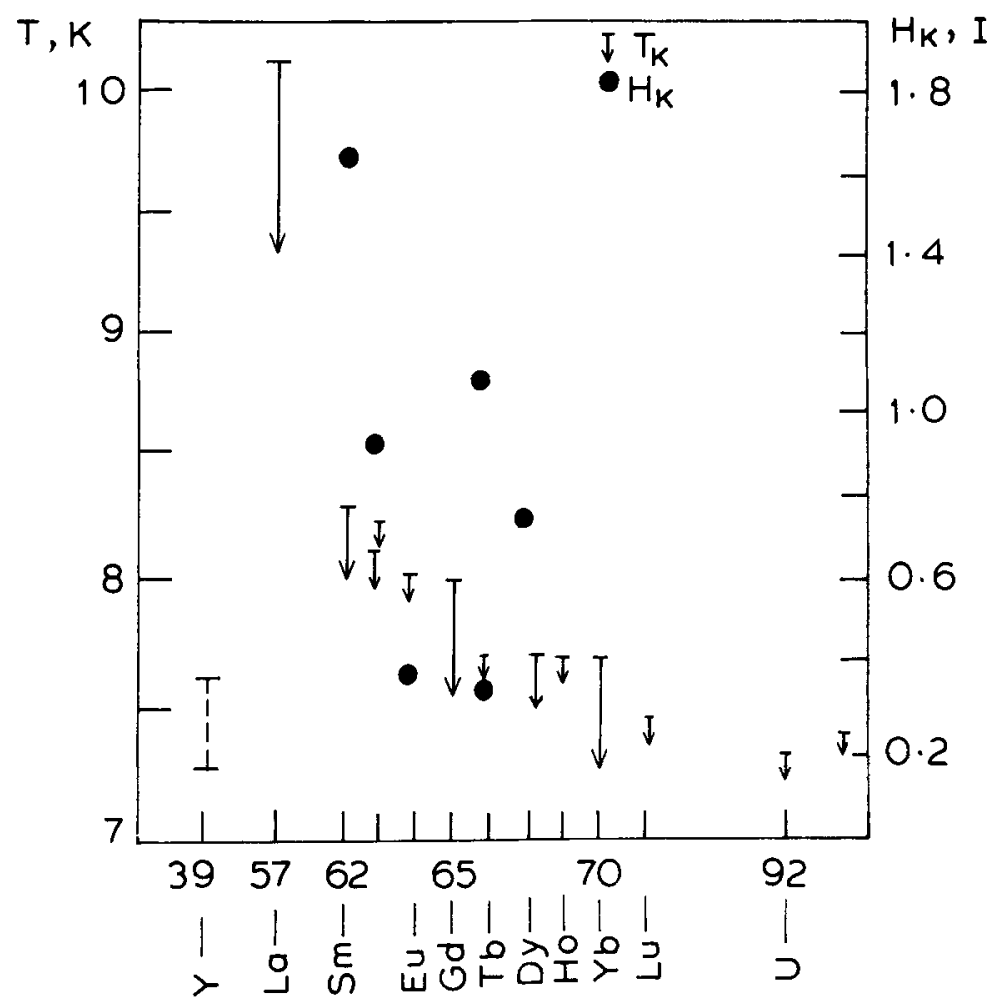

Figure 3. Critical magnetic field $\left(H_{0}\right)$ and critical temperature $T_{c}$ versus atomic number of rare-earth elements for Technetium- $\mathrm{R}_{2} \mathrm{O}_{3}$ cermets. (The beginnings and the ends of arrows indicate the onset and the end of superconducting transition). 


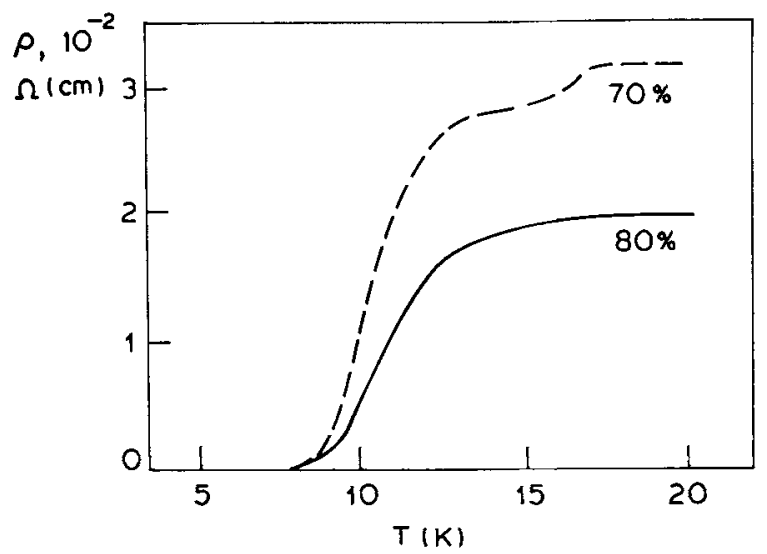

Figure 4. Superconducting transition in superconductor-polymer matrix system.

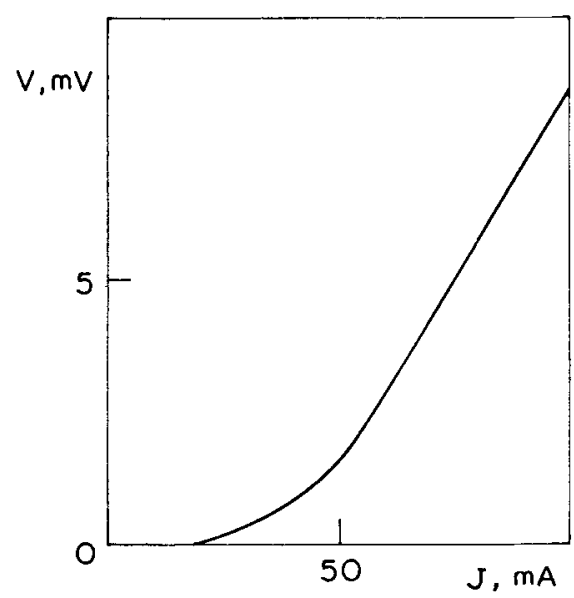

Figure 5. Current vs voltage characteristic of superconductor-polymer matrix system.

Table 1. Some characteristics of molecular cermets and their components.

\begin{tabular}{ccccc}
\hline Ln & $T_{k},\left({ }^{\circ} \mathrm{K}\right)$ & $R_{\mathbf{3 0 0}} / R_{\text {res }}$ & $\begin{array}{c}\text { Metal } \\
\text { content }(\%)\end{array}$ & $\begin{array}{c}\text { Mean size of oxide } \\
\text { phase particles, } \mu \mathrm{m}\end{array}$ \\
\hline $\mathrm{La}$ & $9 \cdot 35$ & - & $50 \cdot 80$ & $5 \cdot 0$ \\
$\mathrm{Sm}$ & $4 \cdot 2$ & 6 & $52 \cdot 30$ & $2 \cdot 3$ \\
$\mathrm{Eu}$ & $7 \cdot 90$ & $17 \cdot 5$ & $52 \cdot 08$ & $3 \cdot 5$ \\
$\mathrm{Gd}$ & $7 \cdot 97$ & $14 \cdot 5$ & $51 \cdot 35$ & $2 \cdot 7$ \\
$\mathrm{~Tb}$ & $7 \cdot 57$ & 12 & $51 \cdot 13$ & $1 \cdot 25$ \\
$\mathrm{Ho}$ & $7 \cdot 52$ & 16 & - & 1.2 \\
$\mathrm{Er}$ & $7 \cdot 58$ & 15 & $26 \cdot 36$ & $1 \cdot 2$ \\
$\mathrm{Yb}$ & $7 \cdot 32$ & 7 & $54 \cdot 60$ & $1 \cdot 15$ \\
$\mathrm{Lu}$ & $7 \cdot 45$ & - & - & $1 \cdot 0$ \\
\hline
\end{tabular}


We feel that the $T_{c}$ increase observed in Technetium- $\mathrm{R}_{2} \mathrm{O}_{3}$ cermets compared to $T_{c}$ of pure Technetium is due to the influence of $\mathrm{R}_{2} \mathrm{O}_{3}$.

We have tried to prepare superconductors in polymer matrix (Alekseev et al 1977). In contrast to the superconducting cermets case, the metal-insulator transition in the superconductor-polymer (unsaturated polymer of fluorine-derivative ethylene) system occurs at a metal concentration of $70 \%$. The $\mathrm{Nb}_{3} \mathrm{Sn}$ powder (grain size $\sim 5 \mu \mathrm{m}$ ) was used as a superconducting metal. Superconductors with polymer matrix were prepared by mixing metallic powder and polymer at $150-200^{\circ} \mathrm{C}$ under pressure. Figure 4 shows the transition to superconducting state of the metal-polymer system for metal concentration $70 \%$ and $80 \%$. The low $J_{c}$ and nonlinear current-voltage characteristic (figure 5) may indicate the existence of tunnelling contacts in such superconductors.

It is also found that samples with $60-65 \% \mathrm{Nb}_{3} \mathrm{Sn}$ indicate high sensitivity to submillimeter radiation (more than $10^{3} \mathrm{v} / \mathrm{w}$ for $8 \mathrm{~mm}$ radiation). The width of the superconducting transition in the superconductor-polymer system is $16-17 \mathrm{~K}$.

\section{References}

Alekseev V A 1972 J. Non Cryst. Solids 8-10 723

Alekseev V A, Vedenov A A, Lelichko A V, Zaitseva L L. Konarev M I, Ryzhkov Yu F, Sukhikh A I, Parshin A I and Shishkov N V 1975 Molecular superconducting cermets; Theses of conference on technical application of superconductivity, Alushta

Alekseev V A, Baranovsky V M, Vedenov A A, Velichko A V, Zaitseva L L, Kovalenko A S, Konarev M T, Leshchenko G F, Mylnikova T S, Ryzhkov Yu F, Skidan B S, Sukhikh A I, Feklina L I, Usov N A, Parshin A I and Shishkov N V 1977 Small-dispersive superconductors in ceramic and polymeric matrix; Superconducting materials, Atomizdat 